\title{
Keepers as social companions: Tactile communication and social enrichment for captive apes
}

\author{
Mirko Cerrone ${ }^{1}$
}

\begin{abstract}
The article addresses the topic of great ape-keeper tactile communication. The aim of this paper is to understand whether direct physical contact can be considered a source of enrichment for captive apes and whether it could be used to enhance animal welfare in zoos. We make use of a multispecies perspective provided by umwelt theory in an attempt to determine the role of touch in zoological gardens. By referring to Konrad Lorenz, we describe keeper-animal relationships as a special case of companionship, highlighting the role of keepers in apes' social behaviour. The paper considers social touch as the primary means used by social animals to create and maintain increasingly complex relationships. Since tactile communication in interspecific contexts has been underestimated previously, our theoretical framework allows for a better understanding of physical contact in zoological gardens without assuming an anthropocentric point of view. Our hypothesis is that physical contact with keepers may provide enriching opportunities for social animals and help strengthen the bond between animals and their keepers. We emphasize that ape-animal interactions in zoos need to involve keeper-animal physical contact as a possible means for enhancing the apes' welfare.
\end{abstract}

Keywords: tactile communication; umwelt; keeper-animal relations; companion; animal welfare

\section{Introduction}

Ethological work has long highlighted the prominent role that tactile communication plays in intraspecific social bonding for the maintenance of social order and internal hierarchy among primates (Dunbar 2010). However, little attention has been paid to touch in interspecies interactions in zoological gardens. This paper addresses the matter of tactile communication between captive apes and

1 Department of Semiotics, University of Tartu, Jakobi 2, 51005 Tartu, Estonia; e-mail: mirko.cerrone@ut.ee. 
keepers. We treat social touch as a species-specific affiliate behaviour and suggest employing it as part of zoos' enrichment strategies to facilitate engaging keepers as active social figures. Here we define enrichment as a change (either an addition or a removal) to the physical and social environment of captive animals with the aim to enhance the psychological and physiological well-being and welfare of the animals (Shepherdson 1998: 1). In recent years, the practice of cognitive enrichment has gained popularity as a means of improving animal well-being (Broom 2010; Clark 2011, 2013, 2017; Clark et al. 2013; Meyer, Puppe, Langbein 2011; Yamanashi et al. 2016). While no generally accepted definition is available, Clark (2011: 6) has defined enrichment as any task "whose use (1) engages evolved cognitive skills by providing opportunities to solve problems and control some aspect of the environment, and (2) is correlated to one or more validated measures of wellbeing". Enrichment programmes are a rather important aspect in the agenda of zoological gardens, and they are a popular strategy used to reduce the stress and boredom of animal populations kept in captivity. The variety of enrichment strategies is quite extensive (Hoy, Murray, Tribe 2010). Approaches to the development of these programmes heavily depend on the species involved; they are also influenced by the personal history of the animal (Newberry 1995). These factors make their analysis and the evaluation of their enriching potential a rather complex subject.

Welfare is connected to the concept of enrichment. However, there exist several definitions of welfare. In this paper, we will use this concept to refer to the physiological and psychological well-being of the animals held in zoos (Dolins 1999). Welfare is influenced by several factors, including husbandry practices, species characteristics, and the individual preferences of the animal (Watters, Wielebnowski 2009: 502). It is quite difficult to establish what could be interpreted as "good" or "bad" for an animal's welfare, and, in our case, whether physical contact (with humans) and tactile communication could have beneficial effects on animals' welfare. The aim of this paper is to offer a holistic approach to social touch as present in primate species to understand better whether interspecies physical contact (keeper-animal) could be used to improve the welfare of social animals. Our initial argument is that the inclusion of keeper-animal physical contact could be successfully added as an instrument to enhance the welfare of apes in zoological gardens. More specifically, we highlight the role of keepers as a source of social enrichment for captive animals and we describe their function considering Lorenz's concept of 'companion' (Lorenz 1937).

The word 'companion' ('Kumpan'), as defined by Lorenz, "means a fellow who is our companion so far as concerns but one particular kind of occupation, such as hunting or drinking" (Lorenz 1937:260), and the term could be better translated 
as 'mate' or 'buddy'. Lorenz borrows this terminology from the Uexküllian tradition (Uexküll, J. von 1992: 369; Brentari 2009). The concept of companion has been linked to the innate release mechanism (IRM), social releaser, and the concept of imprinting (Schleidt 1992: 150). According to this mechanistic view, a companion is any agent able to trigger species-specific behaviour. While a companion is usually a conspecific, its function can potentially be performed by any other subject; this calls attention to the semiotic nature of this concept, which we will discuss in the following. By defining keepers as apes' social companion, we can uncover the social role that keepers play in zoological gardens. We suggest that tactile interactions can be seen as the building blocks of complex social interactions. For this purpose, we refer to the concept of 'umwelt' as developed by Jakob von Uexküll $(1909,1992)$. 'Umwelt' can be defined as the subjective world of an organism that always includes a perceptual and operational side. It is "a qualitative and meaningful model of a species' significant surrounding" (Sebeok 1986: 23). The umwelt is the world that an organism perceives and creates through its actions (Kull 2009: 43). This subjective world is created through what Uexküll called 'the functional cycle' (Uexküll, J. von 1921), a model that connects the input generated in the external world to the animal's behaviour (Brentari 2015: 99) and the process through which an umwelt is constructed. This model is dependent on the perceptive and operational organs of the animal. Since an organism responds only to meaningful signs and not casual impulses (Uexküll, T. von 1992: 285), the functional cycle has been linked to the concept of semiosis (Krampen 1997; Cobley 2010: 347).

As we will discuss in greater detail in the following sections, primates rely quite significantly on social touch for intra-group relations. Social touch, however, can take various forms. Here, we link the concept of 'search tone', as defined by Jakob von Uexküll (1992: 373-376), to that of social touch in order to understand its role in interspecies interactions. A search tone can be defined as something that the subject is looking for when it does not have a precise idea about what it is searching for (Tønnessen 2018), while having an idea of what the function of this object is. If the function of social touch is to establish closer connections with group mates and re-establish social order, as we will discuss in the following sections, we argue that physical contact between keepers and apes may produce similar outcomes, i.e. reduced stress, increased collaboration, and easier husbandry work for the keepers. 


\section{A model for human-animal tactile communication in zoological gardens}

One of the challenges that zoological gardens face is to recreate the in-situ living conditions of the animals they are hosting as much as possible; this includes not only meeting the mere biological needs of the animals, such as climate and dietary requirements, but also the intraspecific social relations that would occur in situ. However, due to monetary and spatial restrictions, this is not always possible. It is no surprise that captive social conditions differ significantly from those observed in the in-situ environment. One clear repercussion is noticeable in the communicative behaviour of animals. The artificial nature of zoos makes it possible for animals to partake in communicative acts that do not typically occur in situ. For example, hybridization following the mating of two different species was a rather common phenomenon in the past, while affiliate surrogate programmes involving dogs (Fritz, Fritz 1985) and multispecies exhibits showcasing animals from different continents (Rees 2011: 131) are still quite common. Whereas hybridization is possible because the two animals involved share at least a certain amount of code that allows them to communicate, positive or neutral (generally non-agonistic) relations in multispecies exhibits find their strength in the compatibility of the species involved, either because of similar climate and dietary requirements or behavioural compatibility, e.g. shared social cues or learned behaviour that allows the pacific coexistence of the two (or more) species. However, zoological gardens remain mostly sites where human-animal relations take place, and this paper will also explore this dimension.

When thinking about human-animal tactile communication, it is important to consider three different interconnected layers. On the first level, we find the institutional legislation that regulates the amount of contact allowed between animals and their keepers; on the next level, we have intraspecific variables and an animal's individual preferences; finally, on the third level, we have human attitudes towards captive animals. These three factors mutually influence the possible types of human-animal interactions that can occur in zoological gardens. We propose a model adapted from the threefold model envisaged by Filip Jaroš (2018), which will serve to conceptualize the factors influencing human-ape relationships in zoos.

Zoological gardens adopt different policies regarding direct contact between animals and their keepers which vary according to different animal species. These policies were created to ensure the safety of the keepers and the welfare of the animals. Contact policies limit the amount of contact that animals can receive from humans. More specifically, a no-contact policy inhibits physical contact 
between keepers and animals. In the case of apes, however, this type of policy clashes with their intraspecific behaviour and communication systems. As we will show in the following sections, most species of apes rely on social touch for bonding. Touch is an essential affiliate behaviour that is used to strengthen social relations and to create new alliances within the group. In this sense, building upon intraspecific behaviour should be the first strategy created to ameliorate animals' social life. Strategies of this kind have been proven to enhance the quality of keeper-animal relationship in previous studies. For example, rhesus macaques responded with increased affiliate behaviour towards their keepers as a response to caretakers who imitated their species-specific communication (Bayne, Dexter, Strange 1993). Finally, keeper-animal relationships are influenced by the keeper's attitude towards the animals. Human attitude can deeply shape the type of relationship formed with the animals and simultaneously have deeper effects upon their welfare and intraspecific behaviour (Cole, Fraser 2018). Thus, it is essential to keep in mind these three aspects when analysing the strength of human-animal bonds in zoological gardens. A non-hierarchical semiotic interpretation of the three layers represented (Fig. 1) allow us to understand and conceptualize the different factors influencing human-ape relationship in zoological gardens. However, since this paper tries to take an emic approach to animal communication, only the first two issues will be addressed: namely, we will discuss the role that contact policies and intraspecific social behaviour play in shaping the quality of keeper-animal relationships.

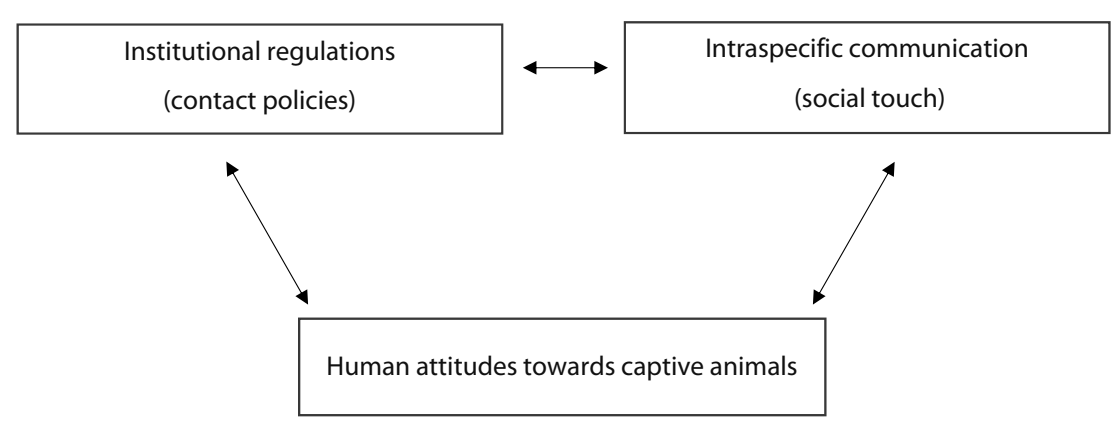

Figure 1. Factors influencing human-animal relationships in zoological gardens. 


\section{Human influence upon captive animals in zoological gardens}

Studies concerning communication between different species have focused on human-animal relationships (HAR) between domestic animals and farmers (Hemsworth, Barnett, Coleman 1993; Hemsworth, Coleman 1998; Jones 1994; Waiblinger et al. 2006). While the concept of HAR has been applied mostly to the study of agricultural animals, it can be adapted to the study of animals in zoos as well (Hosey 2013). However, we need to keep in mind that in the case of zoo animals, we are dealing with animals with no history of domestication, whose behaviour is still somehow affected by anthropogenic changes due to captivity and repeated human interactions. Contact with humans in zoos, be they familiar, such as zookeepers, or strangers (e.g. visitors, temporary staff members), is an essential aspect in the life of any animal living in a zoo. However, previous research has mostly focused on the relationship between animals and visitors (Carder, Semple 2008; Davey 2007; Fernandez et al. 2009; Hosey 2000, 2008, 2013; Margulis, Hoyos, Anderson 2003), with particular attention given to the destructive and negative impact of visitors on the behaviour and psychological state of animals (Chamove, Hosey, Schaetzel 1988; Montanha, Silva, Boere 2009; Rajagopal, Archunan, Sekar 2011; Wells 2005).

Comparatively, there have been far fewer studies focused on the relationships between animals and keepers (Ward, Melfi 2015), with a limited number of studies examining the negative influence of keepers (Hosey, Melfi 2014). A growing body of evidence seems to point out that animal-keeper relationships can have positive effects on animals' welfare (Carrasco et al. 2009; Mellen 1991). Mellen (1991), for example, showed positive correlations between the quality of interactions between felids and keepers and the overall welfare of the animals. Interestingly, he defined positive interactions as those involving "keepers who spent a great deal of time with each cat, soliciting contact and talking to the cat" (Mellen 1991: 99). In this case, physical contact and, generally, tactile interactions, are considered an integral factor to assess the quality of keeper-animal interactions. Chimpanzees in research facilities benefitted from constant social interactions with their human caretakers (Bloomsmith et al. 1999). Moreover, intraspecies aggression in chimpanzees (Bloomsmith et al. 1994) and singly housed rhesus macaques (Bayne 1993) has been successfully reduced thanks to food rewards, which consequentially reduced abnormal behaviour. Instead, increased grooming activity and reduced inactivity have been linked to more frequent human-chimpanzee interactions (Baker 2004).

However, a high number of keepers may have negative influences. For example, higher corticoid levels, which points to higher stress levels, were found in the 
faeces of clouded leopards (Neofelis nebulosa) that had multiple keepers compared to animals who only interacted with a few familiar keepers (Wielebnowski et al. 2002). The quality and frequency of interactions seemed to be unsatisfactory when different keepers are involved, and social bonds could not be successfully formed. Studies focused on the analysis of the quality of keeper-animal interactions (Carlstead 2009) have brought to light the different problematics of the topic. Overlapping issues regarding animals' keeper affinity, species-specific fear of people, and individual behavioural factors, such as curiosity and sociability (Carlstead 2009: 599), complicate the picture.

Research with primates and big feline species confirmed that increased interactions with zookeepers could benefit both the animals and the workers (Szokalski, Litchfield, Foster 2012). Surveys involving keepers of big cats highlighted the great importance given to animal-keeper interactions for husbandry practices, educational purposes, and animal welfare (Szokalski, Litchfield, Foster 2012: 7), while recognizing the significance of no-contact between animals and visitors. While theorizations and studies conducted on the species level may cast light on species-specific preferences regarding physical contact and interactions with the public, it is important to understand the vital role of individual preferences. Singular individuals may respond to same conditions in diametrically opposite ways. Studies conducted with Western lowland gorillas (Gorilla gorilla gorilla) showed that individual gorillas had different reactions to the presence of visitors: visitors had a negative impact (e.g. more aggression, visual scanning) on some groups, while in other zoos visitors seemed to have no effect at all on the animals (Carder, Semple 2008: 217). A third group of gorillas showed positive responses to visitors presence (Stoinski, Jaicks, Drayton 2011), such as less undesirable behaviours and attempts to seek proximity to the visitors. Similarly, increased interactions with keepers resulted in increased tolerance towards visitors in some zoos, while in another zoo gorillas showed more aggression (Mellor, Hunt, Gusset 2015: 74). Previous experience and personal dispositions play an important role in determining an animal's response to enrichment programmes and other variables and, as such, these factors should be carefully considered when interpreting animal behaviour. While species-specific theorizations should serve as a starting point for welfare analyses and enrichment programmes, individual-level preferences can significantly impact the outcomes of welfare examinations.

Some studies have discussed the potential positive effects of visitors upon captive animals (Hosey 2000; Markowitz et al. 1981), mostly suggesting the idea that visitors may represent a source of environmental variability, and as such have the potentiality to enrich captive animals' lives. Empirical evidence seems to support this idea partially, with increased activities directed towards visitors 
in the case of different species of primates (Chamove, Hosey, Schaetzel 1988; Hosey, Druck 1987), especially as regards active visitors (Mitchell et al. 1992), e.g. visitors seeking interactions. Similarly, higher frequency of mother-child contact in the case of chimpanzees (Cook, Hosey 1995) was observed, while other studies reported increased interest in visitors and juvenile-adult interactions in the case of orangutans (Birke 2002). The interpretation of the data, however, proves to be a difficult task. Increased intraspecific affiliative behaviour, such as in the studies conducted by Cook and Hosey (1995) and Birke (2002), could be classified as enriching, given the arguably positive effect upon intraspecific affiliative behaviour. However, we may argue that juvenile orangutans seek adults' companionship, and chimpanzee mothers more often cling to their children because of an increased alert level stemming from a general mistrust of visitors. It can also be argued that visitors represent an environmental variability that reduces boredom and inactivity (Hosey 2008). An analysis of hormone levels (e.g. cortisol), paired with behavioural observations, may provide an answer.

\section{Zoo contact policies: From free contact to zero handling}

Contact policies are extremely important for the training of animals. The use of conditioning techniques, such as the use of a clicker or a whistle and food reinforcement, usually supports this type of training. Different handling policies have different impacts on the use of training techniques and husbandry practices. Safeguarding animal welfare is the priority of these regulations. Thus, physical contact between animals and humans (either visitors or staff members) must be regulated accordingly.

An increasing number of zoos are adopting zero-handling policies and protected contact approaches instead of the free contact policy that was more common earlier (Rees 2011: 238). In the case of free contact, animal and keepers share the same space without any barriers between them. This approach is still used in many zoos when dealing with animals that are considered relatively safe (smaller non-carnivorous mammals, for example). However, it poses several limitations when keepers must work with larger species or with carnivores. For example, great apes pose a severe threat to the lives of caretakers; hence the necessity to regulate physical contact between animals and keepers. Protected contact reduces the risks of a free contact policy thanks to the employment of physical barriers separating the keepers and the animals. While physical contact is still allowed through barriers, this approach ensures that keepers are protected from unexpected attacks by the animals, while the animals are less prone to feel 
trapped, threatened, or stressed (Reinhardt, Cowley 1990; Turkkan 1990). It is also suggested that protected contact contributes to overall animal welfare (Maple, Perdue 2013: 105). Protected contact has successfully reduced the risks associated with husbandry practices and has proved to be a very successful strategy as it makes the cooperation of animals its key factor. Animals' collaboration facilitates transportation and makes medical care and daily husbandry routines easier for the personnel and less stressful for the animals involved (Abadie 1997²; Ball, Fad 2006). Contact between keepers and animals proves to be a precious tool for the formation and maintenance of more solid bonds between the animals and their keepers/carers and for the reduction of stress levels, possibly due to higher environmental control given to the animal (Bassett, Buchanan-Smith 2007; Bayne 2002; Claxton 2011; Hosey, Melfi 2012).

On the other extreme, some zoos have adopted a zero-handling, or hands-off, policy, which means that no contact is allowed between the animals and their keepers. In this case, animals and keepers never share the same physical space. This approach may be supported because it promotes the idea that the animals will not be influenced by the presence of humans, ensuring that their behaviour is closer to that of their ex-situ conspecifics (Kiley-Worthington 2012). It is also believed to ease the work of keepers who do not have physically to enter the animal's enclosure, reducing their exposure to potential attacks. On the other hand, zero-handling policies create difficulties in husbandry work and zoo management. Since these animals are not acclimated to human contact, medical staff must cope with more laborious tasks when veterinarian care is necessary. No cooperation from the animals often means that animals must be tranquillized or restrained even for the most straightforward medical routines. This also implies that, for these animals, veterinarian care produces higher stress levels compared to animals that are used to human contact (Kiley-Worthington 2012).

The European Association of Zoos and Aquaria ${ }^{3}$ (EAZA) guidelines (2014) established instructions for the quantity and quality of direct (physical) contact between animals and humans, with particular focus given to visitor-animal interactions. These standards provide several recommendations regarding physical contact with animals: contact is generally allowed with animals that pose no physical

2 Abadie, Margaret 1997. Medical management of an Asian elephant herd in a protected contact system. Paper presented at the AZA Annual Conference. Retrieved from http:// activeenvironments.org/pdf/Med_Mgmt_Elephants_atHZG.pdf.

3 European Association of Zoos and Aquaria 2014. Standards for the Accommodation and Care of Animals in Zoos and Aquaria. Retrieved from https:/www.eaza.net/assets/Uploads/ Standards-and-policies/Standards-Accommodation-Care-2014-v2.pdf. 
risk for the visitors and only when the welfare of the animals is safeguarded ${ }^{4}$. The EAZA standards provide a detailed list of animals that should be considered dangerous for visitors; this list includes all adult apes. These standards imply that contact between visitors and juvenile apes is allowed, but physical interactions should stop once the animals reach adulthood. This situation occurs quite frequently with young hand-reared apes, who are exposed to everyday interactions with familiar and, sometimes, unfamiliar humans. However, these interactions usually cease once the animal has matured and is introduced to other conspecifics.

\section{Can physical contact be considered enrichment?}

To establish whether direct contact represents a source of enrichment for the animal, and whether it has positive effects on animal welfare, it is necessary to study the impact of human physical contact on intraspecific and stereotypical behaviours. Stereotypical behaviour is here defined as a type of behavioural pattern that is repetitive, invariant in its form, and serves no apparent concrete function (Ödberg 1978; Mason 1991). However, this seems to exclude a more profound acknowledgement of the meaning of physical contact for animals, since the only issue addressed regards its impact on animal welfare. In this sense, if physical contact is not meaningful for the animal and has no apparent negative effects, physical contact could still potentially be allowed. The World Association of Zoos and Aquariums (WAZA) directives, on the other hand, point out the general need to evaluate whether physical contact is necessary (Mellor, Hunt, Gusset 2015: 72), highlighting the necessity to understand its impact on the animal's welfare and that of its conspecifics. Something can be considered enriching only if it proves to be effective in reducing stress and associated stereotypical behaviour (Coviello-McLaughlin, Starr 1997), while increasing species-specific behaviours and introducing variability in the life of the animals (Mellen, MacPhee 2001).

Studies involving different animal species have revealed that individual enriching preferences were influenced by the species-specific repertoire of the animal (Mehrkam, Dorey 2015: 428). Based on these premises, it seems quite tempting to suggest that physical contact may represent a form of enrichment for those animals whose species-specific information exchange depends heavily

4 Hazardous animals, however, are prohibited from entering in contact with visitors, and only limited contact with staff members is allowed. Hazardous animals are those animals that can pose a threat to humans due to their physical strength (i.e. big carnivores), hyper-protective or aggressive behaviour (e.g. during mating season), or because they can injure humans due to being venomous (snakes, venomous frogs). 
upon tactile communication, such as primates or other highly sociable animals, keeping in mind personal-level preferences as highlighted in previous sections. It is also important to bear in mind that while physical contact with an individual may be beneficial in given circumstances, individual and external variables can influence the animal's perception of human touch. For example, a new mother will probably be more skittish and avoid contact while nursing; diseases and intragroup aggression may also affect the way apes react to human contact.

\subsection{Social touch in primates}

The majority of primate societies rely on social touch as a means of communication. The most commonly studied tactile behaviour in primates is grooming. Grooming can be defined as a type of affiliate behaviour, common to many other social animals (Burkett et al. 2016; Kleiman 1967; Kutsukake, Clutton-Brock 2006, 2010; Niesink, Van Ree 1989; Stopka, Graciasova 2001; Wilkinson 1986; Wood 1977). Primates other than humans spend up to $18 \%$ of their daily time grooming (Dunbar 1991). Chimpanzees spend up to $10 \%$ of their time grooming each other (Wrangham 1977; Ghiglieri 1984; Pusey 1990), 70\% of which is in polyadic clusters (Nakamura 2003). Only orangutans, who are less social, spend less than $0.01 \%$ of their time in social grooming (Wich et al. 2009: 196).

One physiological advantage of grooming is stress reduction (Aureli, Preston, de Waal 1999; Feh, de Mazières 1993; Keverne, Martensz, Tuite 1989), but grooming also helps keep one's fur clean from debris and parasites. Although grooming poses several risks for the groomer, such as decreased vigilance, increased vulnerability (Mooring, Hart 1995), and higher energy use, grooming provides obvious social advantages far more appealing than the lower-level "risks" associated with such an activity. It has been shown that the time spent grooming another individual greatly exceeds the actual time required to keep fur clean (Dunbar 2010), bringing forward the idea that social reasons may be behind primates' grooming activity. Grooming seems to be connected to the maintenance and establishment of social relationships. Evidence deriving from observations of blue monkeys (Cercopithecus mitis) suggests a high level of reciprocity in grooming activity (Cords 2002), meaning that time spent grooming seems to be correlated with time spent being groomed, asking to be groomed and the refusal of the activity. Grooming has therefore been described as a "currency" to exchange for a commodity (Henzi, Barrett 1999: 48), and it has been suggested that it is linked to the creation of coalitions against competitive interactions (Cords 2002; Dunbar 1984, 1988; Dunbar, Sharman 1984; Seyfarth 1977; Harcourt 1992; Seyfarth, Cheney 1984). Recent studies have highlighted the complex dynamics 
of grooming practices. In the case of Western chimpanzees (Pan troglodytes verus), groomers choose partners according to personal preferences (e.g. friends) and prospective social benefits (i.e. higher-rank members); however, they avoid grooming group members that have strong social bonds with at least one bystander (Mielke et al. 2018), as the latter will often interfere with grooming activities because of jealousy or to prevent possible change in social hierarchy. Bystanders monitor grooming activities around them and intervene based on their own social position within the group and their awareness of the relationship between the groomers (Mielke et al. 2017). In other words, if a group member initiates a grooming session, there is a chance that this session will be interrupted by a bystander if this activity proves to threaten the social position of the third party within the group.

Generally, post-conflict affiliate interactions include a certain level of physical contact and are aimed to reduce stress after in-group attacks (Fraser, Stahl, Aureli 2008). Tactile comfort has been observed in different species, either with socially close individuals, in case of chimpanzees (Palagi, Paoli, Tarli 2004; Romero, Waal 2010), or with genetically related individuals, in case of macaques (Aureli, Das, Veenema 1997). Consolation of conspecifics was first thought to be exclusive to humans and later recognized to be shared with other primates ${ }^{5}$. Consolation behaviour in primates has been linked to empathy (Webb et al. 2017) and better social integration. Empathetic feelings and consolatory behaviour may give an evolutionary advantage to social animals, in the sense that they both enhance survival chances and benefit the giver in the long term. Supporting fellow members proves to be quite successful in case of external aggression. In this line, affiliative behaviour and "friendships" have been described in intragroup members in the case of female blue monkeys (Cords 2002), while male-to-male friendships are often created among chimpanzees (Goodall 1986; Dagg 2011: 71), especially among siblings, with more current research highlighting the role of trust in the social bonds of chimpanzee (Engelmann, Herrmann 2016).

We share with other primates, and to an extent with other mammals, an inherent need to engage in physical contact with others in order to establish deeper and long-lasting relationships. Interspecies interactions are particularly interesting in this context. Increased interest in pets could be explained as a

5 Recent studies have discovered consolatory behaviour in ravens (Orlaith, Bugnyar 2010), in which physical contact plays a significant role. Additionally, tactile communication plays a significant role in pair-bond birds, with allopreening acting as an instrument to strengthen bonds in species that cooperate to raise their young (Kenny et al. 2017). This behaviour is more common in sociable birds compared to solitary ones, with a positive correlation between the time spent allopreening and group size (Radford, Du Plessis 2008). 
supplementary attempt to find a socially acceptable way to fulfil our tactile needs. Besides the use of animal-assisted therapy (see Nimer, Lundahl 2007 for a review), interactions with domestic animals have also been studied in relation to their positive effects on the psychological and physiological well-being of humans. Direct physical contact with dogs (petting, hugging) has been linked to decreased cortisol levels in children (Beetz et al. 2011), and a reduced heart rate in stressed subjects (Demello 1999). Contact with a companion animal has therefore been addressed as a potential factor in the promotion of social interactions in children and adults (Beetz et al. 2012). The need to experience other living beings through tactile means would explain the existence of petting zoos, where visitors can interact physically with other animals. In a sense, petting zoos supplement part of the sensory experience that is lost in other areas of zoological gardens and allows the visitors to interact with animals not only on visual, auditory, and olfactory levels, but also through tactile means.

\section{Touch and umwelt theory: Parental care and the concept of companion}

Our ability to discern different sensations stems from the somatosensory system, which is an incredibly intricate network of nerve endings and touch receptors beneath the skin. Our skin plays a double role: on the one hand, it separates external agents and protects us from foreign intrusions; on the other hand, it is the layer that links our internal world to the external reality (Hoffmeyer 2008). Once external stimuli are registered through the skin, biological meanings are assigned to these sensations (Hoffmeyer 2008: 19). To make sense of these stimuli our body creates a network of functional interpretations that are promptly acted upon with appropriate responses. It is only through a process of translation and interpretation that external stimuli do not remain isolated impulses but become meaningful entities.

It is also through the sense of touch that internal experiences can be linked to the external social world and increasingly complex interactions can make sense. While this holds true for intraspecific social organization, we are also arguing that also interspecific relationships can benefit from tactile communicative acts. In the case of isolated social animals in zoos (i.e. animals that normally live in groups or in pairs), touch deprivation may have incredibly disruptive effects on the wellbeing of animals. In the context of interspecific interactions, grooming can be used to solidify keeper-animal bonds and as a positive reinforcement strategy. Grooming from staff members during training sessions is a successful substitute 
for food rewards in the case of small primates (Taira, Rolls 1996), probably because of the positive effects on hormone release.

Grooming activity may also be effectively used to relieve stress and act as social bonding for orphaned apes, in the latter case as a substitute for intraspecies affiliate behaviour. However, the suitability and potential effects of human grooming on the mechanics of intraspecific activities needs to be clarified. For example, it has been observed that chimpanzees' grooming style is passed matrilineally (Wrangham et al. 2016). This implies that the way a staff member performs grooming on a chimpanzee could have long-term repercussions on the social integration of the animal or, at the very least, it could introduce variations in the grooming style of other members, i.e. when the hand-reared chimpanzee has her own offspring. Grooming activity, and more generally physical contact with staff members, proves to be a successful tool to establish close connections with the animals and to support the future social integration of chimpanzees (Bashaw, Gullott, Gill 2010; Thunström, Persson, Björklund 2013), provided their early integration into conspecific groups.

However, extensive human contact can negatively affect the individual and social development of animals. Chimpanzees raised as pets or performers struggle to integrate into intraspecific groups (Freeman, Ross 2014). In this latter case, however, it is important to specify that these chimpanzees are often raised in a uniquely human environment, often becoming more humanized in their behaviour, in the case of pets, or mistreated if raised as performers. Still, it is possible that the later introduction of other conspecifics will result in poor integration, regardless of the quantity and quality of human contact received. This is due to the existing limited timeframe that regulates the successful recognition of conspecifics, as we will now move on to discuss in more detail.

Social touch in apes can vary significantly; however, the exact way social touch changes must be understood better. Social touch is linked to intrinsic speciesspecific behaviour, which can be tied to the unusually long period of maternal care that primates undergo. Primates are born helpless and without proper maternal care they would soon die. Chimpanzees are only weaned when they are five years old (Stanton et al. 2014), similarly for bonobos, for gorillas around the age of three (Eckardt et al. 2016), and in the case of Bornean orangutans (Pongo pygmaeus wurmbii) up to seven years (Noordwijk et al. 2013). Long maternal care characterizes other mammals as well, yet while maternal care can be defined as a primary characteristic of mammalian species, it can be argued that primates carry and hold their infants more than other mammals. We suggest that the meaning of touch has its roots in the early life stages of highly sociable primates (with nursing, carrying, and warmth as signs of parental care), and is extended 
into the adulthood of animals as a tool used to strengthen social bonding and to maintain social order. Group size, as discussed above, increases the time spent looking for and acting on tactile interactions; hence we argue that it is through tactile connections that social bonds are maintained and created in the first place. It is through social touch that increasingly complex relationships in large groups can be preserved and internal coherence can be safeguarded.

The need to be held, or simply to have direct physical interaction, is so rooted in the mammalian umwelt that we believe this could be used in interspecies interactions and zoo management. The tactile need could be interpreted as a special case of search tone, as defined in the introduction of this paper. When the subject (ape) is looking for a grooming partner (usually another conspecific), the initiator has an idea of what the function of this object is (social engagement, cleaning); however, this function may be performed by different actors. Thus, the keeper can also perform this social function and engage in tactile exchange building upon intraspecific behaviour. Physical contact in interspecies interactions is highly influenced by the body part involved in the tactile exchange. For example, cows use licking for positive interactions and social support (Sato 1984) as well as to reduce social tension in a group (Waiblinger, Menke, Coleman 2002). Research on dairy cows showed that petting and grooming body parts that are usually licked by conspecifics had positive effects on milk production, stress relief, and in diminishing fear of humans (Schmied, Boivin, Waiblinger 2008). Other studies showed similar results with horses (Feh, de Mazières 1993). Given these premises, human stimulation could be used to achieve similar results in zoos. It is important to establish in what ways human touch can be successfully used to facilitate the integration of apes in social groups, supplement the lack of maternal contact, or simply form social relations with an animal. Specifically, it is unclear whether all body parts have the same meaning for the animal when touched. In the case of apes, the areas more often groomed are those that are not easily accessible by the groomee (i.e. the back); thus, we suggest that keepers should similarly focus on these regions.

The relationship created between humans and captive apes can elicit the release of intraspecific behaviours and proves to be potentially enriching. Keepers may become apes' companions (Lorenz 1937). As discussed earlier, the concept of companionship is used to describe specific roles played by conspecifics. The companion "serves as a releaser for several specific performances (Leistungen) of behaviours" (Schleidt 1992: 150), as such it might seem that the companion is nothing more than an object that triggers a species-specific trait. However, signification processes lie behind the process of recognition and continuous interactions between companions, and thus the concept of companion is linked 
to that of semiosis. From Uexküll's point of view, the existence of individual-level recognition among conspecifics and their precise and unique relations are signs of environmental enrichment typical of higher animals (Brentari 2015: 137). In this sense, social species need to organize their environment with the aid of perceptive marks and operative marks that allow the recognition of conspecifics at an individual level too. Social species need to be able to recognize individuals in larger groups for the organization of social life, nest building, protection, and feeding their offspring among other things. We can hardly imagine highly sociable animals that are unable to recognize members of their own species, let alone closely related members, who may be either genetically related or "friends", as defined in previous sections. The recognition of individual members and social interactions are based on meaning processes. There is a dialogical relationship with others that is made explicit by the different roles that social animals can play within a group. From observations of birds it seems that during a bird's life cycle, the animal naturally seeks to build relationships of some kind with different partners. In the case of birds, Lorenz identified five types of companions: the parent-companion, the child-companion, the sex-companion, the socialcompanion, and the brother-and-sister-companion (Lorenz 1937: 272). These roles, however, are more flexible than they appear to be; often a subject can transcend a particular role and perform more than one role (e.g. the brotherand-sister-companion can also be a social-companion). According to different environmental conditions and personal experiences, the companion-roles can be fulfilled by various agents. There exists a critical period where birds learn to recognize members of their species and get attached to their parents (Lorenz 1937; Spalding 1954); similar processes are present in mammalian species (Sluckin 1968). If during this period they are exposed not to their conspecifics but to other animal species (or even moving objects), these birds will recognize the latter as one of their parents. In examining the phenomenon, Uexküll wrote:

Clearly, there is no uniform perceptual image for the companion in the jackdaw's world. Nor could there be one since the role of companion changes all the time. In most cases, the receptor image of the mother companion is not determined at birth as to form and color. [...] the same thing happens in choosing the love companion. Here, too, the acquired sign of the substitute companion is created once the first exchange has occurred. In consequence, even animals of the same species are rejected as love companions. (Uexküll, J. von 1992: 371-372)

From this point of view, while the fulfilment of these roles touches upon certain innate mechanisms, the object that can fit into a determined role varies considerably. It is important to understand that the roles played by a companion 
are quite flexible. These social relations are heavily dependent on several external and internal factors, such as individual experience, personal predispositions, and environmental factors. Companions are engaged in complex social roles that could not easily be explained solely through genetics.

In the normal conditions of a zoo, the ape-keeper relationship does not fit entirely into any of the categories proposed by Lorenz. The closest approximation is that of the social companion. According to Lorenz, the releasing functions of the social-companion include: (a) inducing of reaction by "contagion" or imitation; (b) releasing of following reactions; (c) responses to warning; (d) social attack reactions; (e) the interlocking of instinctive actions pertaining to the pecking order and to nest-protection; and (f) responses to the disappearance of the social-companion (Lorenz 1937: 272). From our point of view, however, keepers remain borderline figures, able to elicit responses in case of disappearance (habitual keepers), while new keepers may induce feelings of stress and fear. Keepers are able to influence the social organization of the group and might be able to supplement emotional and cognitive stimulation that has beneficial effects on intra-group relations (Bloomsmith et al. 1999). Human-animal bonds can successfully be created in zoos following regular, positive interactions; a strong attachment level can also be derived from such interactions. Besides, keeperanimal interactions create new types of relationships and interspecific meanings. Zoological gardens are hybrid environments where new meanings and norms are established through constant interactions. As such, interspecies relationships find their strength in shared interests, meanings, and affections (Lestel 2004) which are dialogically constructed in hybrid environments.

While it is relatively easy to understand the attachment level of humans to animals (e.g. Hosey et al. 2018), evaluating the presence of an interspecies bond from an animal's point of view is much more difficult. Behavioural observation is obviously one answer. Human-animal bonds can have a beneficial effect on the wellbeing of an animal; however, strong bonds may also present several drawbacks. The sudden absence or disappearance of a keeper can distress an animal and negatively impact its wellbeing (Hosey et al. 2018: 274). Additionally, abnormal housing is rather common in zoos. Several animal species that in situ lead a solitary or semi-solitary life (such as the orangutan) are forced to share a common space with conspecifics; similarly, some others must maintain longterm relationships with the same group members, even though group associations in situ tend to be much more elastic and liable to change, as in the case of chimpanzees (Lawick-Goodall 1968). On the other extreme, social animals in zoos may in fact live in solitude for reasons such as the death of other conspecifics, particularly aggressive behaviour towards other group members, health problems, 
or the zoo's inability to find suitable companions. Hence, these animals find themselves in living conditions that can alter their usual social interactions. This alteration can impinge on their welfare and lead to dramatic consequences, and human contact can help mitigate some of the associated problems. The development of trustworthy and solid relationships between animals and their keepers has the potential to provide enriching opportunities to the animal on the social and cognitive levels; the human companion also has the ability to elicit intraspecific behaviour, especially in those cases in which intraspecific stimulation is not enough for the animal, and create new interspecific meanings. As discussed earlier, human contact can facilitate social interactions and the integration of difficult subjects. More intimate bonds also benefit keepers who may feel less alienated in their work and thus can benefit from their positive relationships with animals in their work routine. Evidence suggests that keepers' attitude towards animals influences their handling style and, consequently, the animals' responses to their keepers (Ward, Melfi 2015). This implies that if a keeper feels detached from the animals that they take care of, their handling style may have lasting, negative influences on the animals' perception of human contact. Keepers could partially provide tactile comfort when required, provided non-invasive and safe techniques have been established for both parties.

\section{Conclusion}

Tactile communication plays a prominent role in intraspecific group organization, social engagement, and group cohesion for social animals such as apes. We proceed from the premise that physical interaction is one of the fundamental instruments used by social beings to make sense of their social world. We argue that for social animals such as apes, tactile communication creates opportunities to orchestrate complex social interactions, to engage in group dynamics, and maintain internal peace. In the case of apes, social touch functions as a bonding agent that simultaneously strengthens and brings change to group interactions. Grooming, in particular, defined as a currency to use in exchange of favours (Henzi, Barrett 1999: 48), is the most typical form of tactile communication found in apes. Grooming transcends the mechanical and practical function to keep one's fur free from debris and parasites but rather acquires a richer social meaning following Dunbar's hypothesis (2010). If tactile communication plays a prominent role in intraspecies interactions, we argue that physical contact in zoological gardens between keepers and apes has the potential to benefit animals and workers. Reports suggest that human contact during the nursing period has 
positive effects on the social integration of chimpanzees (Bashaw et al. 2010; Thunström et al. 2013). Additionally, building deeper relationships with animals could lead to better job satisfaction for workers.

Drawing on Lorenz's work, we describe animal-human bonds as a special case of companionship. Keepers may function as social companions in the umwelt of captive apes and, as such, they have the potential to elicit intraspecific behaviour, reduce group aggression, and enrich apes' living conditions. Furthermore, new meanings and behaviours are created through continuous interspecies interactions in hybrid environments. Elements of shared life, including meanings, interests, and affections, enable new types of relationships to be built. Keeperanimal relationships should be looked at more closely in order to highlight their capacity to unveil new types of semiotic processes. By looking at keepers as apes' companions, we have uncovered their role in providing social stimulation to captive animals. In this sense, keepers can be regarded as active participants in apes' social lives, and as such they can improve the animals' welfare by supplying enriching opportunities to them. In this paper, we have expressed the idea that it is through physical contact that social relationships are formed and maintained. As such, zoological gardens should look closely at how (social) touch can be utilized to maximise animal welfare. We use Jakob von Uexküll's concept of umwelt that has been employed to uncover the perceptual and operational side of tactile experiences. We have connected the "tactile need" of apes and other primates to the concept of search tone as described by Uexküll. By looking at the need to touch and be touched as a special case of search tone we have created a connection between the way apes and humans search for physical contact with others.

Protected contact proves to be the most successful strategy to handle apes. This is true for several reasons, among which are lower stress levels compared to nocontact policies in cases when veterinarian checks are necessary; it offers increased environmental control to the animals at the same time as ensuring keepers' safety, unlike free contact policies. Moreover, protected contact allows physical interactions to happen between animals and keepers in a safe way and seems to be the most enriching practice and should thus be encouraged. We highlight the necessity of considering tactile communication in the enrichment programmes and welfare analyses of zoological gardens. Enrichment on the tactile level needs to be included in the agenda of zoos in order to provide all-rounded sensorial and cognitive stimulation to social species. Keepers' roles should be more emphasized as their relationship with the animals influences captive animals' lives on several levels. Future research should focus attention on the topic of sensorial enrichment, with particular attention to the sense of touch, since it tends to be neglected more than the other senses. It is important to study the mechanical ways in which touch 
should be performed so that it acquires significance for the animal, and to map the body parts that have the potential of being meaning-carriers when touched. A zoosemiotic approach could provide the necessary instructions for the creation of a model to be used for interspecies tactile interactions in zoos, keeping in mind the species and individual-level preferences of each animal.

\section{References}

Aureli, Filippo; Das, Marjolijn; Veenema, Hans C. 1997. Differential kinship effect on reconciliation in three species of macaques (Macaca fascicularis, M. fuscata, and M. Sylvanus). Journal of Comparative Psychology 111(1): 91-99.

Aureli, Filippo; Preston, Stephanie D.; de Waal, Frans B. M. 1999. Heart rate responses to social interactions in free-moving rhesus macaques (Macaca mulatta): A pilot study. Journal of Comparative Psychology 113(1): 59-65.

Baker, Kate C. 2004. Benefits of positive human interaction for socially housed chimpanzees. Animal Welfare 13(2): 239-245.

Ball, Ray; Fad, Otto 2006. Serum cortisols in captive Asian elephants (Elephas maximus) in different management systems at Busch Gardens Tampa Bay. 2006 Proceedings American Association of Zoo Veterinarians. Tampa: American Association of Zoo Veterinarians, 177-180.

Bashaw, Meredith J.; Gullott, Rebecca L.; Gill, Emily C. 2010. What defines successful integration into a social group for hand-reared chimpanzee infants? Primates 51(2): 139-47.

Bassett, Lois; Buchanan-Smith, Hannah M. 2007. Effects of predictability on the welfare of captive animals. Applied Animal Behaviour Science 102(3/4): 223-245.

Bayne, Kathryn A. L. 2002. Development of the human-research animal bond and its impact on animal well-being. ILAR Journal 43(1): 4-9.

Bayne, Kathryn A. L.; Dexter, Sandra L.; Strange, Gretchen M. 1993. The effect of food treat provisioning and human interaction on the behavioral well-being of rhesus monkeys (Macaca mulatta). Contemporary Topics in Laboratory Animal Science 32(2): 6-9.

Beetz, Andrea; Kotrschal, Kurt; Turner, Dennis C.; Hediger, Karin; Uvnäs-Moberg, Kerstin; Julius, Henri 2011. The effect of a real dog, toy dog and friendly person on insecurely attached children during a stressful task: An exploratory study. Anthrozoös 24(4): 349-368.

Beetz, Andrea; Uvnäs-Moberg, Kerstin; Julius, Henri; Kotrschal, Kurt 2012. Psychosocial and psychophysiological effects of human-animal interactions: The possible role of oxytocin. Frontiers in Psychology 3(234): 1-15.

Birke, Lynda 2002. Effects of browse, human visitors and noise on the behavior of captive orangutans. Animal Welfare 11(2): 189-202.

Bloomsmith, Mollie A.; Baker, Kate C.; Ross, Stephen K.; Lambeth, Susan P. 1999. Comparing animal training to non-training human interaction as environmental enrichment for chimpanzees. American Journal of Primatology 49(1): 35-36.

Bloomsmith, Mollie A.; Laule, Gail E.; Alford, Patricia; Thurston, Robert H. 1994. Using training to moderate chimpanzee aggression during feeding. Zoo Biology 13(6): 557-566.

Brentari, Carlo 2009. Konrad Lorenz's epistemological criticism towards Jakob von Uexküll. Sign Systems Studies 37(3/4): 637-662. 
- 2015. Jakob von Uexkull: The Discovery of the Umwelt between Biosemiotics and Theoretical Biology. (Biosemiotics 9.) Dordrecht: Springer.

Broom, Donald M. 2010. Cognitive ability and awareness in domestic animals and decisions about obligations to animals. Applied Animal Behaviour Science 126(1/2): 1-11.

Burkett, James P.; Andari, Elissar; Johnson, Zachary V.; Curry, Daniel C.; Waal, Frans B. M. de; Young, Larry J. 2016. Oxytocindependent consolation behavior in rodents. Science 351(6271): 375-378.

Carder, Gemma; Semple, Stuart 2008. Visitor effects on anxiety in two captive groups of western lowland gorillas. Applied Animal Behaviour Science 115(3/4): 211-220.

Carlstead, Kathy 2009. A comparative approach to the study of keeper-animal relationships in the zoo. Zoo Biology 28(6): 589-608.

Carrasco, Lara; Colell, Montserrat; Calvo, Miguel; Abello, Maria Teresa; Velasco, Margarita; Posada, Sandra 2009. Benefits of training/playing therapy in a group of captive lowland gorillas (Gorilla gorilla gorilla). Animal Welfare 18(1): 9-19.

Chamove, Arnold S.; Hosey, Geoffrey R.; Schaetzel, Peter 1988. Visitors excite primates in zoos. Zoo Biology 7(4): 359-369.

Clark, Fay E. 2011. Space to choose: Network analysis of social preferences in a captive chimpanzee community, and implications for management. American Journal of Primatology 73(8): 748-757.

- 2013. Marine mammal cognition and captive care: A proposal for cognitive enrichment in zoos and aquariums. Journal of Zoo and Aquarium Research 1(1): 1-6.

- 2017. Cognitive enrichment and welfare: Current approaches and future directions. Animal Behavior and Cognition 4(1): 52-71.

Clark, Fay E.; Davies, Samuel L.; Madigan, Andrew W.; Warner, Abby J.; Kuczaj, Stan A. 2013. Cognitive enrichment for bottlenose dolphins (Tursiops truncatus): Evaluation of a novel underwater maze device. Zoo Biology 32(6): 608-619.

Claxton, Anna M. 2011. The potential of the human-animal relationship as an environmental enrichment for the welfare of zoo-housed animals. Applied Animal Behaviour Science 133(1/2): 1-10.

Cobley, Paul 2010. The Routledge Companion to Semiotics. London: Routledge.

Cole, Jusine; Fraser, David 2018. Zoo animal welfare: The human dimension. Journal of Applied Animal Welfare Science 21(1): 49-58.

Cook, Shelley; Hosey, Geoffrey R. 1995. Interaction sequences between chimpanzees and human visitors at the zoo. Zoo Biology 14(5): 331-440.

Cords, Marina 2002. Friendship among adult female blue monkeys (Cercopithecus mitis). Columbia University Academic Commons 139(2): 291-314.

Coviello-McLaughlin, Gina M.; Starr, Shari J. 1997. Rodent enrichment devices - Evaluation of preference and efficacy. Contemporary Topic in Laboratory Animal Science 36(6): 66-8.

Dagg, Anne I. 2011. Animal Friendships. Cambridge: Cambridge University Press.

Davey, Gareth 2007. Visitors' effects on the welfare of animals in the zoo: A review. Journal of Applied Animal Welfare Science 10(2): 169-183.

Demello, Lesley R. 1999. The effect of the presence of a companion-animal on physiological changes following the termination of cognitive stressors. Psychology \& Health 14(5): 859-868.

Dolins, Francine L. 1999. Attitudes to Animals: Views in Animal Welfare. New York: Cambridge University Press. 
Dunbar, Robin I. M. 1984. Reproductive Decisions: An Economic Analysis of Gelada Baboon Social Strategies. Princeton: Princeton University Press.

- 1988. Primate Social Systems. London: Chapman \& Hall.

- 1991. Functional significance of social grooming in primates. Folia Primatologica 57(3): 121-131.

- 2010. The social role of touch in humans and primates: Behavioural function and neurobiological mechanisms. Neuroscience and Biobehavioral Reviews 34(2): 260-268.

Dunbar, Robin I. M.; Sharman, Martin 1984. Is social grooming altruistic? Zeitschrift für Tierpsychologie 64(2): 163-173.

Eckardt, Winnie; Fawcett, Katie; Fletcher, Alison W. 2016. Weaned age variation in the Virunga mountain gorillas (Gorilla beringei beringei): Influential factors. Behavioral Ecology and Sociobiology 70(4): 493-507.

Engelmann, Jan M.; Herrmann, Esther 2016. Chimpanzees trust their friends. Current Biology 26(2): 252-256.

Feh, Claudia; Mazières, Jeanne de 1993. Grooming at a preferred site reduces heart-rate in horses. Animal Behaviour 46(6): 1191-1194.

Fernandez, Eduardo J.; Tamborski, Michael A.; Pickens, Sarah R.; Timberlake, William 2009. Animal-visitor interactions in the modern zoo: Conflicts and interventions. Applied Animal Behaviour Science 120(1/2): 1-8.

Fraser, Orlaith N.; Stahl, Daniel; Aureli, Filippo 2008. Stress reduction through consolation in chimpanzees. Proceedings of the National Academy of Sciences of the United States of America 105(25): 8557-8562.

Freeman, Hani D.; Ross, Stephen R. 2014. The impact of atypical early histories on pet or performer chimpanzees. PeerJ 2(1): 1-16.

Fritz, Jo; Fritz, Paul 1985. The hand-rearing unit: Management decisions that may affect chimpanzee development. In: Graham, Charles E.; Bowen, James A. (eds.) Clinical Management of Infant Great Apes. New York: Alan R. Liss, Inc., 1-34.

Ghiglieri, Michael P. 1984. The Chimpanzees of Kibale Forest: A Field Study of Ecology and Social Structure. New York: Columbia University Press.

Goodall, Jane 1986. The Chimpanzees of Gombe: Patterns of Behavior. Cambridge: Belknap Press.

Harcourt, Alexander 1992. Coalitions and alliances: Are primates more complex than nonprimates? In: Harcourt, Alexander; Waal, Frans B. M. de (eds.), Coalitions and Alliances in Humans and Other Animals. Oxford: Oxford University Press, 445-472.

Hemsworth, Paul H.; Barnett, John L.; Coleman, Grahame J. 1993. The human-animal relationship in agriculture and its consequences for the animal. Animal Welfare 2(1): 33-51.

Hemsworth, Paul H.; Coleman, Grahame J. 1998. Human-Livestock Interactions: The Stockperson and the Productivity of Intensively Farmed Animals. Wallingford: CABI.

Henzi, Peter S.; Barrett, Louise 1999. The value of grooming to female primates. Primates 40(1): 47-59.

Hoffmeyer, Jesper 2008. Biosemiotics: An Examination into the Signs of Life and the Life of Signs. Scranton: University of Scranton Press.

Hosey, Geoffrey R. 2000. Zoo animals and their human audiences: What is the visitor effect? Animal Welfare 9(4): 343-357.

- 2008. A preliminary model of human-animal relationships in the zoo. Applied Animal Behaviour Science 109(2-4) 105-127. 
- 2013. Hediger revisited: How do zoo animals see us? Journal of Applied Animal Welfare Science 16(4): 338-359.

Hosey, Geoffrey R.; Birke, Lynda; Shaw, Wendy S.; Melfi, Vicky 2018. Measuring the strength of human-animal bonds in zoos. Anthrozoös 31(3): 273-281.

Hosey, Geoffrey R.; Druck, Patricia L. 1987. The influence of zoo visitors on the behavior of captive primates. Applied Animal Behavior Science 18(1): 19-29.

Hosey, Geoffrey R.; Melfi, Vicky 2012. Human-animal bonds between zoo professionals and the animals in their care. Zoo Biology 31(1): 13-26.

- 2014. Are we ignoring neutral and negative human-animal relationships in zoos? Zoo Biology 34(1): 1-8.

Hosey, Geoffrey R.; Skyner, Lindsay J. 2007. Self-injurious behavior in zoo primates. International Journal of Primatology 28(6): 1431-1437.

Hoy, Julia M.; Murray, Peter J.; Tribe, Andrew 2010. Thirty years later: Enrichment practices for captive mammals. Zoo Biology 29(3): 303-316.

Jaroš, Filip 2018. Cat cultures and threefold modelling of human-animal interactions: On the example of Estonian cat shelters. Biosemiotics 11(3): 365-386.

Jones, Bryan R. 1994. Regular handling and the domestic chick's fear of human beings: Generalisation of response. Applied Animal Behaviour Science 42(2): 129-143.

Kenny, Elspeth; Birkhead, Tim R.; Green, Jonathan P. 2017. Allopreening in birds is associated with parental cooperation over offspring care and stable pair bonds across years. Behavioral Ecology 28(4): 1142-1148.

Keverne, Eric B.; Martensz, Nicholas D.; Tuite, Bernadette 1989. Beta-endorphin concentrations in cerebrospinal fluid of monkeys are influenced by grooming relationships. Psychoneuroendocrinology 14(1/2): 155-161.

Kiley-Worthington, Marthe 2012. Exploding the Myths: Mammal Welfare, Handling and Teaching. London: Xlibris Corporation.

Kleiman, Devra G. 1967. Some aspects of social behavior in the Canidae. American Zoologist $7(2): 365-372$.

Krampen, Martin 1997. Models of semiosis. In: Posner, Roland; Robering, Klaus; Sebeok, Thomas A. (eds.), Semiotics: A Handbook on the Sign-Theoretic Foundations of Nature and Culture. Berlin: Walter de Gruyter, 247-287.

Kull, Kalevi 2009. Umwelt and modelling. In: Cobley, Paul (ed.), The Routledge Companion to Semiotics. London: Routledge, 43-56.

Kutsukake, Nobuyuki; Clutton-Brock, Tim H. 2006. Social functions of allogrooming in cooperatively breeding meerkats. Animal Behaviour 72(5): 1059-1068.

- 2010. Grooming and the value of social relationships in cooperatively breeding meerkats. Animal Behaviour 79(2): 271-279.

Lawick-Goodall, Jane van 1968. The behaviour of free-living chimpanzees in the Gombe stream reserve. Animal Behaviour Monographs 1(3): 161-311.

Lestel, Dominique 2004. Lanimal singulier. Paris: Seuil.

Lorenz, Konrad 1937. The companion in the bird's world. Auk 54(1): 245-273.

Maple, Terry L.; Perdue, Bonnie M. 2013. Zoo Animal Welfare. Heidelberg: Springer.

Margulis, Susan W.; Hoyos, Catalina; Anderson, Meegan 2003. Effect of felid activity on zoo visitor interest. Zoo Biology 22(6): 587-599. 
Markowitz, Hal; Stevens, Victor J.; Mellen, Jill D.; Barrow, Barbara C. 1981. Performance of a mandrill (Mandrillus sphinx) in competition with zoo visitors and computer on a reactiontime game. Acta Zoologica et Pathologica Antverpiensia 76: 169-180.

Mason, Georgia J. 1991. Stereotypies: A critical review. Animal Behaviour 41: 1015-1037.

Mehrkam, Lindsay R.; Dorey, Nicole R. 2015. Preference assessments in the zoo: Keeper and staff predictions of enrichment preferences across species. Zoo Biology 34(5): 418-430.

Mellen, Jill D. 1991. Factors influencing reproductive success in small captive exotic felids (Felis spp.): A multiple regression analysis. Zoo Biology 10(2): 95-110.

Mellen, Jill D.; MacPhee, Marty S. 2001. Philosophy of environmental enrichment: Past, present, and future. Zoo Biology 20(3): 211-226.

Mellor, David J.; Hunt, Susan; Gusset, Markus 2015. Caring for Wildlife: The World Zoo and Aquarium Animal Welfare Strategy. Gland: WAZA Executive Office.

Meyer, Susann; Puppe, Birger; Langbein, Jan 2011. Cognitive enrichment in zoo and farm animals - implications for animal behaviour and welfare. Berliner und Münchener Tierärztliche Wochenschrift 123(11/12): 446-456.

Mielke, Alexander; Preis, Anna; Samuni, Liran; Gogarten, Jan F.; Wittig, Roman M.; Crockford, Catherine 2018. Flexible decision-making in grooming partner choice in sooty mangabeys and chimpanzees. Royal Society Open Science 5(7): 1-13.

Mielke, Alexander; Samuni, Liran; Preis, Anna; Gogarten, Jan F.; Crockford, Catherine; Wittig, Roman M. 2017. Bystanders intervene to impede grooming in Western chimpanzees and sooty mangabeys. Royal Society Open Science 4(11): 1-16.

Mitchell, Gary; Tromborg, Chris; Kaufman, Jennifer; Bargabus, Shawna; Simoni, Rosileen; Geissler, Victor 1992. More on the influence of zoo visitors on the behavior of captive primates. Applied Animal Behaviour Science 35(2): 189-198.

Montanha, Julio C.; Silva, Segio L; Boere, Vanner 2009. Comparison of salivary cortisol concentrations in jaguars kept in captivity with differences in exposure to the public. Ciência Rural 39(6): 1745-1751.

Mooring, Mike S.; Hart, Benjamin L. 1995. Costs of allogrooming in impala: Distraction from vigilance. Animal Behaviour 49(5): 1414-1416.

Nakamura, Michio 2003. 'Gatherings' of social grooming among wild chimpanzees: Implications for evolution of sociality. Journal of Human Evolution 44(1): 59-71.

Newberry, Ruth 1995. Environmental enrichment: Increasing the biological relevance of captive environments. Applied Animal Behaviour Science 44(2/4): 229-243.

Niesink, Raymond J. M.; Van Ree, Jan M. 1989. Involvement of opioid and dopaminergic systems in isolation-induced pinning and social grooming of young rats. Neuropharmacology 28(4): 411-418.

Nimer, Janelle; Lundahl, Brad 2007. Animal-assisted therapy: A meta-analysis. Anthrozoös 20(3): 225-238.

Noordwijk, Maria van; Willems, Erik; Utami Atmoko, Sri S.; Kuzawa, Christopher; Schaik, Carel van 2013. Multi-year lactation and its consequences in Bornean orangutans (Pongo pygmaeus wurmbii). Behavioural Ecology and Sociobiology 67(5): 805-814.

Ödberg, Frank O. 1978. Abnormal behavior: Stereotypies. In: Proceedings of the First World Congress of Ethology Applied to Zootechnics. Madrid: Industrias Grafices Espana, 475-480.

Orlaith, Fraser N.; Bugnyar, Thomas 2010. Do ravens show consolation? Responses to distressed others. PLOS ONE 5(5): 1-8. 
Palagi, Elisabetta; Paoli, Tommaso; Tarli, Silvana B. 2004. Reconciliation and consolation in captive bonobos (Pan paniscus). American Journal of Primatology 62(1): 15-30.

Pusey, Anne E. 1990. Behavioural changes at adolescence in chimpanzees. Behaviour 115(3/4): 203-46.

Radford, Andrew N.; Du Plessis, Morné A. 2008. Dual function of allopreening in the cooperatively breeding green woodhoopoe, Phoeniculus purpureus. Behavioral Ecology and Sociobiology 61(2): 221-230.

Rajagopal, Thangavel; Archunan, Govindaraju; Sekar, Mahadevan 2011. Impact of zoo visitors on the fecal cortisol levels and behaviour of an endangered species: Indian blackbuck (Antelope cervicapra L.). Journal of Applied Animal Welfare Science 14(1): 18-32.

Rees, Paul A. 2011. An Introduction to Zoo Biology and Management. Chichester: WilleyBlackwell.

Reinhardt, Viktor; Cowley, Doug 1990. Training stumptailed monkeys (Macaca arctoides) to cooperate during in-homecage treatment. Laboratory Primate Newsletter 29(4): 9-10.

Romero, Teresa; Waal, Frans B. M. de 2010. Chimpanzee (Pan troglodytes) consolation: Thirdparty identity as a window on possible function. Journal of Comparative Psychology 124(3): 278-286.

Sato, Syusuke 1984. Social licking pattern and its relationships to social dominance and live weight gain in weaned calves. Applied Animal Behavior Science 12(1/2): 25-32.

Schleidt, Wolfang M. 1992. Biological bases of age specific behaviour - the companions in man's world. Evolution \& Cognition 1(2): 147-159.

Schmied, Claudia; Boivin, Xavier; Waiblinger, Susanne 2008. Stroking different body regions of dairy cows: Effects on avoidance and approach behavior toward humans. Journal of Dairy Science 91(2): 596-605.

Sebeok, Thomas A. 1986. I Think I Am A Verb: More Contributions to the Doctrine of Signs. New York: Plenum Press.

Seyfarth, Robert M. 1977. A model of social grooming among adult female monkeys. Journal of Theoretical. Biology 65(4): 671-698.

Seyfarth, Robert M.; Cheney, Dorothy L. 1984. Grooming, alliances and reciprocal altruism in vervet monkeys. Nature 308(5959): 541-543.

Shepherdson, David J. 1998. Tracing the path of environmental enrichment in zoos. In: Shepherdson, David J.; Mellen, Jill D.; Hutchins, Michael (eds.), Second Nature: Environmental Enrichment for Captive Animals. Washington: Smithsonian Institution, 1-14.

Sluckin, Wladyslaw 1968. Imprinting in guinea-pigs. Nature 220(5172): 1148-1148.

Spalding, Douglas A. 1954. Instinct with original observations on young animals. The British Journal of Animal Behaviour 2(1): 2-11.

Stanton, Margaret A.; Lonsdorf, Elizabeth V.; Pusey, Anne E.; Goodall, Jane; Murray, Carson M. 2014. Maternal behavior by birth order in wild chimpanzees (Pan troglodytes): Increased investment by first-time mothers. Current Anthropology 55(4): 483-489.

Stoinski, Tara S.; Jaicks, Hannah F.; Drayton, Lindsey A. 2011. Visitor effects on the behavior of captive western lowland gorillas: The importance of individual differences in examining welfare. Zoo Biology 31(5): 586-599.

Stopka, Pavel; Graciasova, Romana 2001. Conditional allogrooming in the herb-field mouse. Behavioral Ecology 12(5): 584-589.

Szokalski, Monika S.; Litchfield, Carla A.; Foster, Wendy K. 2012. What can zookeepers tell us about interacting with big cats in captivity? Zoo Biology 32(2): 142-151. 
Taira, Kosei; Rolls, Edmund T. 1996. Receiving grooming as a reinforcer for the monkey. Physiology \& Behaviour 59(6): 1189-1192.

Thunström, Maria; Persson, Tomas; Björklund, Mats 2013. Integration of a hand-reared chimpanzee (Pan troglodytes) infant into a social group of conspecifics. Primates 54(1): 13-9.

Tønnessen, Morten 2018. The search image as link between sensation, perception and action. Biosystems 164: 138-146.

Turkkan, Jaylan 1990. New methodology for measuring blood pressure in awake baboons with use of behavioral training techniques. Journal of Medical Primatology 19(5): 455-466.

Uexküll, Jakob von 1909. Umwelt und Innenwelt der Tiere. Berlin: Springer.

- 1921. Umwelt und Innenwelt der Tiere 2. Vermehrte Und Verbesserte Auflage. Berlin: Springer.

- 1992. A stroll through the worlds of animals and men: A picture book of invisible worlds. Semiotica 89(4): 319-391.

Uexküll, Thure von 1992. Introduction: The sign theory of Jakob von Uexküll. Semiotica 89(4): 279-315.

Waiblinger, Susanne; Boivin, Xavier; Pedersen, Vivi; Tosi, Maria V.; Janczak, Andrew M.; Visser, Kathalijne E.; Jones, Robert B. 2006. Assessing the human-animal relationship in farmed species: A critical review. Applied Animal Behaviour Science 101(3/4): 185-242.

Waiblinger, Susanne; Menke, Christoph; Coleman, Grahame 2002. The relationship between attitudes, personal characteristics and behaviour of stockpeople and subsequent behaviour and production of dairy cows. Applied Animal Behaviour Science, 79(3) 195-219.

Ward, Samantha J.; Melfi, Vicky 2015. Keeper-animal interactions: Differences between the behaviour of zoo animals affect stockmanship. PLOS ONE 10(10): 1-10.

Watters, Jason V.; Wielebnowski, Nadja 2009. Introduction to the special issue on zoo animal welfare. Zoo Biology 28(6): 501-506.

Webb, Christine E.; Romero, Teresa; Franks, Becca; Waal, Frans B. M. de 2017. Long-term consistency in chimpanzee consolation behaviour reflects empathetic personalities. Nature Communications 8(292): 1-8.

Wells, Deborah L. 2005. A note on the influence of visitors on the behaviour and welfare of zoo-housed gorillas. Applied Animal Behaviour Science 93(1/2): 13-17.

Wielebnowski, Nadja C.; Fletchall, Norah; Carlstead, Kathy; Busso, Juan M.; Brown, Janine L. 2002. Noninvasive assessment of adrenal activity associated with husbandry and behavioral factors in the North American clouded leopard population. Zoo Biology 21(1): 77-98.

Wich, Serge A.; Utami-Atmoko, Sri S.; Mitra Setia, Tatang; Schaik, Carel P. van 2010. Orangutans: Geographic Variation in Behavioral Ecology and Conservation. New York: Oxford University Press.

Wilkinson, Gerald S. 1986. Social grooming in the common vampire bat, Desmodus rotundus. Animal Behavior 34(6): 1880-1889.

Wood, Mark T. 1977. Social grooming patterns in two herds of monozygotic twin dairy cows. Animal Behavior 25(3): 635-642.

Wrangham, Richard W. 1977. Feeding behaviour of chimpanzees in Gombe National Park, Tanzania. In: Clutton-Brock, Tim H. (ed.), Primate Ecology: Studies of Feeding and Ranging Behaviour in Lemurs, Monkeys and Apes. London: Academic Press, 504-538.

Wrangham, Richard W.; Koops, Kathelijne; Machanda, Zarin P.; Worthington, Steven; Bernard, Andrew B.; Brazeau, Nicholas F.; Donovan, Ronan; Rosen, Jeremiah; Wilke, Claudia; Otali, Emily; Muller, Martin N. 2016. Distribution of a chimpanzee social custom is explained by matrilineal relationship rather than conformity. Current Biology 26(22): 3033-3037. 
Yamanashi, Yumi; Matsunaga, Masayuki; Shimada, Kanae; Kado, Ryuichiro; Tanaka, Masayuki 2016. Introducing tool-based feeders to zoo-housed chimpanzees as a cognitive challenge: Spontaneous acquisition of new types of tool use and effects on behaviours and use of space. Journal of Zoo and Aquarium Research 4(3): 147-155.

\section{Сотрудники зоопарка как социальные компаньоны: тактильное общение и социальное обогащение для обезьян в неволе}

Цель настоящей статьи - понять, можно ли рассматривать прямой контакт с телом как источник обогащения для обезьян в неволе и можно ли его использовать для повышения благосостояния животных в зоопарках. Мы используем многовидовую перспективу, предоставленную теорией умвельта, пытаясь установить роль тактильных контактов в зоопарках. Опираясь на Конрада Лоренца, мы описываем отношения смотрителя и животного как особый случай товарищества, подчеркивая роль смотрителей в социальном поведении обезьян. Социальное прикосновение определяется в статье как основное средство, используемое социальными животными для создания и поддержания всё более сложных отношений. Поскольку тактильная коммуникация в межвидовых контекстах ранее недооценивалась, наши теоретические рамки позволяют лучше понять телесный контакт в зоопарках, не принимая антропоцентрической точки зрения. Наша гипотеза состоит в том, что физический контакт со смотрителями может предоставить обогащающие возможности социальным животным и помочь укрепить связь между животными и смотрителями. Мы вносим свой вклад в обсуждение взаимодействия человека и животного в зоопарках, выдвигая необходимость включения контакта между человеком и животным в качестве возможного средства повышения благосостояния обезьян.

\section{Talitajad kui sotsiaalsed kaaslased: taktiilne kommunikatsioon ja sotsiaalne rikastamine vangistuses elavate inimahvide puhul}

Artikkel käsitleb inimahvide ja talitajate vahelise taktiilse kommunikatsiooni teemat. Uurimuse eesmärgiks on mõista, kas otsest füüsilist kontakti võib vangistuses viibivate inimahvide puhul pidada rikastamise allikaks ning kas seda võiks kasutada loomade heaolu parandamiseks loomaaedades. Püüdes määratleda puudutuse rolli loomaaedades kasutame omailmateooria pakutavat mitmeliigilisuse perspektiivi. Viidates Konrad Lorenzile, kirjeldame talitaja ja looma vahelisi suhteid kaaslassuhte erijuhtumina, rõhutades talitajate rolli ahvide sotsiaalses käitumises. Artiklis peetakse sotsiaalset puudutust peamiseks vahendiks, mille abil sotsiaalsed loomad loovad ning säilitavad üha keerukamaid suhteid. Et taktiilset kommunikatsiooni on liikidevahelistes suhetes varasemalt alahinnatud, võimaldab meie teoreetiline raamistus paremini mõista loomaaedades esinevaid füüsilisi kontakte, ilma et asutaks antropotsentristlikule vaatekohale. Meie hüpotees on, et füüsiline kontakt talitajatega võib sotsiaalsetele loomadele pakkuda rikastavaid võimalusi ning aidata tugevdada loomade ja talitajate vahelist sidet. Rõhutame, et inimahvide ja inimeste vahelise suhtlemisega loomaaedades peaks ahvide heaolu suurendamise võimaliku allikana kaasnema talitaja ja looma vaheline füüsiline kontakt. 